NASA Technical Memorandum 100581

\title{
ACTIVE COOLING DESIGN FOR SCRAMJET \\ ENGINES USING OPTIMIZATION METHODS
}

\author{
(MASA-TH-100581) ACTIVE CCCIIXG DESIGN FOB N88-20669 \\ SCEAHJET ENGINES CSIHG CPTIEIZATICN METHCES \\ (IASA) $13 \mathrm{~F}$ \\ CSCL 20K \\ Unclas \\ G3/39 0135289
}

Stephen J. Scotti

Carl J. Martin

Stephen H. Lucas

MARCH 1988

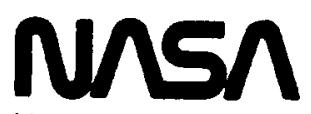

National Aeronautics and

Space Administration

Langley Research Conter

Hampton, Virginia 23665-5225 


\title{
ACTIVE COOLING DESIGN FOR SCRAMJET ENGINES USING OPTIMIZATION METHODS
}

\author{
Stephen J. Scotti \\ NASA Langley Research Center \\ Hampton, Va. 23665 \\ Carl J. Martin \\ PRC Kentron Inc. \\ Hampton, Va. 23666 \\ Stephen H. Lucas \\ ViRA Inc. \\ Hampton, Va. 23666
}

\begin{abstract}
A methodology for using optimization in designing metallic cooling jackets for scramjet engines is presented. The optimal design minimizes the required coolant flow rate subject to temperature, mechanical-stress, and thermal-fatiguelife constraints on the cooling-jacket panels, and Mach-number and pressure constraints on the coolant exiting the panel. The analytical basis for the methodology is presented, and results for the optimal design of panels are shown to demonstrate its utility.
\end{abstract}

\begin{tabular}{|c|c|}
\hline \multicolumn{2}{|r|}{ Nomenclature } \\
\hline$a$ & $=$ sonic velocity \\
\hline$A$ & $=$ surface area \\
\hline$a_{\text {eq }}$ & $=$ equivalent annular plate outer radius \\
\hline$A_{f}$ & $=$ flow area \\
\hline$b_{\text {eq }}$ & $=$ equivalent annular plate inner radius \\
\hline$C_{1}, C_{2}$ & $=$ coefficients in eqns. (13) and (14) \\
\hline$C_{i j}$ & $=$ material constants for fatigue calculations \\
\hline$d$ & $=$ pin base diameter \\
\hline$D_{h}$ & $=$ hydraulic diameter for channel fins \\
\hline$D^{\prime}$ & $=$ coolant passage volume divided by wetted area \\
\hline$E$ & $=$ Young's modulus \\
\hline$E_{f}$ & $=$ frictional energy loss \\
\hline$f^{\prime}$ & $=$ Fanning friction factor \\
\hline$F$ & $=$ objective function \\
\hline $\mathbf{G}$ & $=$ vector of constraint functions or their limits \\
\hline$h$ & $=$ channel height, pin height, specific enthalpy \\
\hline$L$ & $=$ flow length for pressure drop calculation \\
\hline$\dot{m}$ & $=$ coolant mass flow rate \\
\hline$M$ & $=$ coolant Mach number \\
\hline$N$ & $=$ number of pin rows in flow direction \\
\hline$N_{i j}$ & $\begin{aligned}= & \text { number of cycles at conditions } i j \\
& \text { before fatigue failure }\end{aligned}$ \\
\hline$N_{f}$ & $=$ number of mission cycles before fatigue failure \\
\hline$N u$ & $=$ Nusselt number \\
\hline$p$ & $=$ coolant pressure \\
\hline $\operatorname{Pr}$ & $=$ Prandtl number \\
\hline$q$ & $=$ incident heat flux \\
\hline$r$ & $=$ pin fillet radius \\
\hline$R e$ & $=$ Reynolds number \\
\hline$s$ & $=$ channel width, pin spacing \\
\hline$t$ & $=$ outer wall thickness \\
\hline$T$ & $=$ temperature \\
\hline$w$ & $=$ channel wall thickness \\
\hline$x$ & $=$ distance from entrance of cooling panel \\
\hline $\mathbf{X}$ & $=$ vector of design variables or their limits \\
\hline$\alpha$ & $=$ coefficient of thermal expansion \\
\hline & $=$ strain range \\
\hline
\end{tabular}

$$
\begin{array}{ll}
\gamma_{i j} & =\text { material constants for fatigue calculations } \\
\rho & =\text { coolant density } \\
\sigma & =\text { stress }
\end{array}
$$

subscripts

$i \quad=$ coolant conditions at entrance or exit of a segment

in, out $=$ coolant conditions at entrance and exit of the panel

$\lim , \mathrm{l}, \mathrm{u} \quad=$ limiting value, lower and upper limits

$p c, p p=$ load conditions for fatigue calculations

pl $\quad=$ plastic

ref $\quad=$ reference conditions

inner, outer=inner and outer facesheets of cooling jacket

\section{Introduction}

The resurgence of interest in hypersonic flight has spurred a corresponding interest in high-temperature structures. The extreme heating environments of vehicles such as the Aerospace Plane and the "Orient Express" require an extension of the progress made in the structures research of the last two decades. One of the most demanding challenges in hightemperature, hypersonic structures is the design of the hydrogen-fueled, scramjet engine for the vehicle. A scramjet engine is an airbreathing propulsion system which combusts a fuel such as hydrogen in a supersonic airstream. Because of the high density and total enthalpy of the air flow, the heating of the structure wetted by the airstream can be extreme. Peak heating rates in the combustor of a scramjet can easily exceed $2000 \mathrm{Btu} / \mathrm{ft}^{2}$-sec, a level which requires an active cooling system to maintain the walls at a survivable temperature. The cooling system which has shown the most promise for engine cooling applications is a system of hydrogen-fuel-cooled, metallic, surface heat exchangers (cooling jackets) attached directly to the engine primary structure (see reference 1 , a summary of the research into convectively cooled structures during the 1960's and 1970's).

In the design of most aerospace structures, the design goal is typically a minimum weight design. However in this study, the design goal is to minimize the required flow rate of coolant. The reasons for this choice of design goal follow. Energy balance methods have been used to predict the hydrogen fuel flow rate required to cool the scramjet engine of a hypersonic vehicle; however even using these simple methods, the coolant requirement exceeds the fuel flow rate for optimum engine performance at Mach numbers greater than about ten (ref. 2). This increase in fuel flow rate to provide engine cooling has a significant effect on the amount of fuel 
a vehicle requires to complete its mission. Viewed a different way, it may cause the required size of a vehicle designed to perform a mission to undergo a large increase. The results found in these past studies are optimistic since the internal performance of the surface heat exchangers (that is, the overall cooling system effectiveness) has not been considered in determining the cooling requirements for the scramjet engine. Heat exchanger performance along with additional thermal and structural requirements on the cooling-jacket structure may increase cooling needs far above those calculated using a simple energy balance. Since the cooling system is only a minor contributor to the engine weight, but the major factor in determining the required coolant flow rate, this paper presents a method for designing engine cooling jackets and determining coolant conditions which minimizes the required flow rate of coolant.

The cooling-jacket design method of the present study uses numerical optimization as a design tool. Numerical optimization is a practical approach to the design of coolingjacket systerns since many design requirements can be considered simultaneously. The optimization goal is to design cooling jackets which minimize the required coolant flow rate for specified heating rates. The design must also satisfy design requirements such as material limits on cooling-jacket temperature, stress, and fatigue life as well as limits on coolant Mach number and pressure drop through the coolant passages.

Geometries for two cooling-jacket concepts, namely channel-fin and pin-fin concepts, are studied in this application of the design methodology. The approximate analytical methods used to predict performance of these cooling-jacket systems with these geometries and the use of formal optimization to couple the analyses to produce optimum designs are explained. Results of the optimization of a single heated panel are presented for various combinations of materials, heating rates, and inlet pressure limits. The single panel cases demonstrate the applicability of the methodology for cooling-jacket design and for sensitivity analysis with respect to certain de sign parameters. These cases also illustrate the existence of strong coupling between the different design constraints. Additionally, some results of a three-panel system of cooling jackets are given to illustrate flow routing effects.

\section{Scramiet and Cooling-Jacket Geometry Description}

A schematic showing the location of a scramjet engine on the lower surface of a hypersonic vehicle is given in the upper portion of figure 1. From this schematic, the smooth integration of the engine with the vehicle lower surface in front of the engine (the forebody) and behind the engine (the afterbody) is apparent. This integration of vehicle with engine improves vehicle performance.

A conceptual, two-dimensional scramjet engine cross section is shown in the middle of figure 1 . The engine consist of a series of ramps (which may be movable) that merge with the vehicle lower surface, and a cowl which helps capture the air compressed by the vehicle fuselage and the engine ramps. For a fixed Hight condition, there are no moving parts in the scramjet engine except for the fuel pumps. Not shown in the figure are the sidewalls which connect the cowl to the ramps to form a two-dimensional flow passage. The major components of the engine are the inlet, combustor, and nozzle.

A typical engine ramp heat flux distribution is shown in the lower portion of figure 1 . The combustor section experiences the highest heat flux. The nozzle and the inlet experi- ence lower heat fluxes with the inlet having the lowest. Typical ramp heat fluxes assumed for demonstrating the design methodology are 1000 to $2000 \mathrm{Btu} / \mathrm{ft}^{2}-\mathrm{sec}$ for the combustor, $300 \mathrm{Btu} / \mathrm{ft}^{2}-\mathrm{sec}$ for the nozzle, and $150 \mathrm{Btu} / \mathrm{ft}^{2}$-sec for the inlet. All three components require active cooling. The engine cowl and sidewalls along with portions of the vehicle forebody and afterbody also require active cooling, however, these areas are not considered in the present study since they can be designed using the same procedure as the ramp panels.

The geometries of channel-fin and pin-fin cooling jackets are illustrated in figure 2. For channel-fin cooling jackets, the geometry can be completely described by the channel width $(s)$, the channel height $(h)$, the channel wall thickness $(w)$, and the outer wall (outer facesheet) thickness ( $t$ ). Assuming the pins are located at the vertices of equilateral triangles, the geometry of pin-fin cooling jackets is characterized by the pin spacing $(s)$, the pin base diameter $(d)$, the pin height $(\mathrm{h})$, the pin fillet radius $(r)$, and the outer wall thickness $(t)$.

\section{Analvtical Basis for Design Methodology}

This section presents a brief description of the analytical models used to evaluate the performance of the cooled panels. The design requirements which must be satisfied in the design methodology are limits on material temperature, coolant pressure drop and Mach number, cooling-jacket stress and low-cycle-fatigue life. Since numerical optimization requires the repeated evaluation of these quantities, simple and computationally efficient models are used. A given cooled panel is divided into segments along the flow length (fig. 3), and the coolant flow conditions, as well as each of the design requirements, are evaluated at the exit of each segment. A brief description of the various analytical models which describe the actively cooled panel performance follows.

\section{Coolant Flow Analysis}

Figure 3 illustrates the division of the cooling-jacket panel into segments of length $L$ for purposes of the analysis. Coolant flow and heat flux are assumed to be uniform across the width of the panel, and thus the coolant and structural temperatures do not vary across the panel width. Below the panel in figure 3 is a representative segment with entrance temperature $T_{i}$ and pressure $p_{i}$. It is subjected to heat flux $q_{i}$, and the coolant enthalpy rise through the segment is

$$
h_{i+1}-h_{i}=\frac{q_{i} A}{\dot{m}}
$$

where $A$ is the segment heated surface area, $h_{i}$ and $h_{i+1}$ are enthalpies at the segment entrance and exit, and $\dot{m}$ is the coolant mass flow rate. The coolant temperature at the exit of the segment $\left(T_{i+1}\right)$ is determined using hydrogen gas property routines (ref. 3 ) which determine gas temperature for given enthalpies and pressure. The relationship used is

$$
T_{i+1}=f\left(h_{i+1}, p_{i+1}\right) \approx f\left(h_{i+1}, p_{i}\right)
$$

The approximate relationship in (2) is valid because the temperature-enthalpy relationship is only a weak function of pressure, and the pressure drops across segments are small.

The coolant pressure drop across a segment is given by the expression

$$
p_{i+1}-p_{i}=E_{f}+\left(\frac{\dot{m}}{A_{f}}\right)^{2}\left(\frac{1}{\rho_{i+1}}-\frac{1}{\rho_{i}}\right)
$$


where $E_{f}$ represents the frictional energy loss, $\rho_{i}$ and $\rho_{i+1}$ are the coolant densities at the segment inlet and exit, and $A_{f}$ is the flow area. The frictional energy loss is expressed in slightly different forms for the channel-fin and pin-fin cooling jackets. For flow in channels, $E_{f}$ is expressed as

$$
E_{f}=\left(\frac{\dot{m}}{A_{f}}\right)^{2} \frac{4 f L}{D_{h}\left(\rho_{i}+\rho_{i+1}\right)}
$$

where $L$ is the segment flow length, and $D_{h}$ is the hydraulic diameter. The Fanning friction factor $(f)$ is a function of the coolant flow Reynolds number $(R e)^{\prime}$ and is given by (ref. 4)

$$
f=0.046 R e^{-0.2}
$$

The frictional pressure drop for pin-fin sections has been investigated in references 5 and 6 . With frictional energy loss expressed as

$$
E_{f}=\left(\frac{\dot{m}}{A_{f}}\right)^{2} \frac{4 f N}{\left(\rho_{i}+\rho_{i+1}\right)}
$$

the friction factor data shows little Reynolds number dependence, and a single value of $f=0.09$ is used in all the pin fin calculations. In (6), $N$ is the number of pin rows in flow length $L$. The flow area $\left(A_{f}\right)$ used in $(3)$ and $(6)$ for pin fins is the minimum flow area.

Coolant flow rate is an input quantity in the analysis, and the pressure drop which actually controls the flow rate is determined by a side calculation. When the cooling-jacket optimization is complete, the flow rate and pressure drop are properly balanced, however, during the optimization process, the pressure drop calculation (eqn. 3) often leads to situations where the pressure drop through a segment may be higher than the inlet pressure. To avoid the difficulties associated with unrealistic negative pressures, a pressure mapping scheme was devised to handle the occurance of negative pressures during the cooling-jacket optimization. A description of the pressure mapping scheme is given in Appendix A.

To avoid compressibility effects, a limit is needed for the Mach number of the coolant flow. The Mach number is calculated by

$$
M=\frac{\dot{m}}{\rho a A_{f}}
$$

where all the coolant conditions are evaluated at the panel exit. The area $A_{f}$ in (7) is taken as the minimum coolant flow area for the pin-fin jackets.

\section{Determination of Cooling-Jacket Temperatures}

Once the coolant conditions at the exit of a segment are determined, the temperature distribution through the cooling jacket at the segment exit (the hottest location in a segment) is evaluated. The first step is to compute the film coefficient for convective heat transfer using published correlations. The correlation developed in reference 7 are used for the channelfin cooling jacket. In this reference, film coefficients for turbulent flows of hydrogen in tubes are correlated over a wide range of temperatures and heat fluxes. The correlation is

$$
N u=.023 \operatorname{Re}^{.8} \operatorname{Pr}^{.4}\left(T_{s} / T\right)^{-\left(.57-1.59 D_{h} / x\right)}
$$

where $T$ is the bulk coolant temperature and $T_{s}$ is the tube surface temperature. The Nusselt number $(N u$, a dimensionless measure of the convective heat transfer), Reynolds number $(R e)$, and Prandtl number $(P r)$ are all evaluated at the bulk coolant conditions. Also in (8), $D_{h}$ is the hydraulic diameter, and $x$ represents the distance from the cooling-jacket entrance.

Heat transfer for short $(1 / 2<h / d<4)$, cylindrical pin fins has been investigated by several authors (refs. $5,6,8$ through 11) for turbine blade cooling applications. The data are well represented by the following correlation (ref. 8)

$$
N u_{D^{\prime}}=.153 R e_{D^{\prime}}^{.685}
$$

The characteristic dimension $D^{\prime}$ in the Reynolds and Nusselt numbers is defined as the coolant passage volume divided by its wetted surface area .

The cooling-jacket temperature distribution is calculated using simple one-dimensional conduction and convection finite element models. Conduction and convection areas are calculated based on the geometries of the cooling jackets shown in figure 2. Schematic representations of the onedimensional channel-fin and pin-fin models are illustrated in the lower portion of figure 3. Symmetries are used to reduce the model size. The lower surface is assumed to be an adiabatic boundary since the amount of heat transferred through the inner wall is small compared to the heat going into the coolant. The surfaces where convective heat transfer occurs are also shown in figure 3 . Material thermal conductivities are included as functions of the average cooling-jacket temperature in the one-dimensional models. Detailed two- and threedimensional finite element models verified the accuracy of temperatures computed from the simple models to be within ten percent over a wide range of geometries, convective film coefficients, and thermal conductivities.

\section{Mechanical Stresses}

To insure that structurally feasible cooling-passage geometries are maintained in the design process, mechanical stresses due to the containment of the high pressure coolant are computed at critical locations. These computations, based on simple conceptual models of the structure and handbook formulae (ref. 12), are described below. For the channelfin geometry, stresses are evaluated at two locations, the channel wall and the outer wall (fig. 2). Tensile stress in the channel wall is expressed as

$$
\sigma_{w}=\frac{p s}{w}
$$

where $p$ is the coolant pressure, and the dimensions $s$ and $w$ are shown in figure 2 . The bending stress in the outer wall is also evaluated. The wall is modeled as a beam of length $s+w$ fixed at the channel walls. The coolant pressure supplies a uniform load. The bending stress in the outer wall is

$$
\sigma_{b}=\frac{p}{2} \frac{(s+w)^{2}}{t^{2}}
$$

Stresses in the pin-fin jacket are evaluated at three points (fig. 2). The tensile stress in the cylindrical pin is

$$
\sigma_{p}=p \frac{s^{2} \cos 30^{\circ}-(\pi / 4) d^{2}}{(\pi / 4) d^{2}}
$$

The bending stress in the outer wall of the pin-fin jacket is evaluated at two locations (fig. 2) and is based on the handbook formula for stress in a circular plate fixed at the inner and outer radii (ref. 12). The stresses for this case are

$$
\begin{aligned}
& \sigma_{\text {outer }}=C_{1} a_{\mathrm{eq}}^{2} \frac{6 p}{t^{2}} \\
& \sigma_{\text {inner }}=C_{2} a_{\mathrm{eq}}^{2} \frac{6 p}{t_{\mathrm{eq}}^{2}} .
\end{aligned}
$$


The values of $C_{1}$ and $C_{2}$ are functions of the ratio of the outer to inner radii $\left(b_{\text {eq }} / a_{\text {eq }}\right)$ as given in reference 12 . Modifications to (13) and (14) to account for the fillet radius $(r)$ are made by defining equivalent plate radii and thickness (denoted by the subscript eq) as

$$
\begin{aligned}
& b_{\mathrm{eq}}=d / 2+\frac{r^{2}}{4(t+.35 r)} \\
& a_{\mathrm{eq}}=s / 2 \\
& t_{\mathrm{eq}}=t+\left(r-\sqrt{r^{2}-\left(r+d / 2-b_{\mathrm{eq}}\right)^{2}}\right)\left(1.45 \frac{b_{\mathrm{eq}}}{d}\right)^{3 / 2}
\end{aligned}
$$

Equations (15) through (17) were determined by correlation with finite element analyses.

\section{Thermal Stress and Low-Cycle-Fatigue Life}

The extreme heat flux environment of engine panels can produce large thermal gradients and thermal stresses in the cooling jackets. The combination of large thermal strains and high operating temperature may result in plastic deformation and creep in the outer wall of a cooling jacket. The dominant thermal stresses (and strains) result from the large temperature differences between the cooling-jacket outer wall and the inner wall attached to the engine structure. These large thermal strains can lead to low-cycle-fatigue (LCF) cracking and failure. The following section briefly explains the formulation of the LCF analysis and the application of the Strainrange Partitioning (SRP) method (ref. 13) used in this design procedure.

The applications presented consider only a simple mission cycle beginning at a reference temperature (i.e. room temperature), changing to a single flight condition, and returning to the reference temperature. Also, it is assumed that the inner wall and the attached engine structure are much stiffer than the outer wall. Thus, all the mechanical strain due to temperature gradients occurs in the outer wall of the cooling jacket. Using these assumptions, the total thermally induced, mechanical strainrange for a cycle is

$$
\epsilon_{\text {total }}=\alpha_{\text {outer }}\left(T_{\text {outer }}-T_{\text {ref }}\right)-\alpha_{\text {inner }}\left(T_{\text {inner }}-T_{\text {ref }}\right)
$$

where $\alpha$ is the coefficient of thermal expansion. The life relationships in the SRP method are based on the plastic strainrange. This is estimated by assuming elastic-perfectly plastic material behavior. The geometries of channel-fin and pinfin cooling jackets tend to produce strain concentrations in the thinnest sections as indicated by test results in reference 14. To account for this, a strain concentration factor of 1.5 is used. Thus, the plastic strainrange over a cycle may be expressed as

$$
\epsilon_{\mathrm{pl}}=1.5\left(\epsilon_{\text {total }}-2 \sigma_{\text {yield }} / E\right)
$$

The combination of high stress and high temperature results in creep of most materials. This creep, which is compressive under compressive stress, contributes to the LCF of the outer wall. The detailed time and temperature history of the engine necessary for predicting creep is beyond the scope of this study. However, since some materials are damaged by creep more than others, some consideration of creep is necessary. In this work, creep effects on LCF are included by assuming a compressive creep strainrange of ten percent of the plastic strainrange for each cycle. The two cyclic strain conditions of relevance in the fatigue of the outer wall are $\epsilon_{p p}$ (tensile plastic strain reversed by compressive plastic strain) and $\epsilon_{p c}$ (tensile plastic strain reversed by compressive creep). The $\epsilon_{p p}$ strainrange is simply the plastic strainrange, and the $\epsilon_{p c}$ strainrange is the compressive creep strainrange given by the previous creep assumption. Thus,

$$
\begin{aligned}
\epsilon_{p p} & =\epsilon_{\mathrm{pl}} \\
\epsilon_{p c} & =0.1 \epsilon_{\mathrm{pl}} \\
\epsilon_{\text {inelastic }} & =\epsilon_{p p}+\epsilon_{p c}
\end{aligned}
$$

where $\epsilon_{\text {inelastic }}$ is the total inelastic strainrange for a cycle. The failure relationships for the different strainrange types are determined experimentally; but ductilitity relationships (ref. 15) may be used for materials that are not well characterized. Once the plastic and creep strainranges are calculated, the SRP method is used to predict the low-cycle-fatigue life. The cyclic life relationships for the various strainranges are expressed in the form

$$
N_{i j}=C_{i j} \epsilon_{\text {inelastic }}^{\gamma_{i j}}
$$

where $i j$ is either $p p$ or $p c, N_{i j}$ is the cycles to failure for the given strainrange, and $C_{i j}$ and $\gamma_{i j}$ are material constants. The cyclic life $\left(N_{f}\right)$ for the cooling-jacket outer wall is predicted by the interactive damage rule (ref. 14)

$$
\frac{1}{N_{f}}=\frac{1}{\epsilon_{\text {inelastic }}}\left[\frac{\epsilon_{p p}}{N_{p p}}+\frac{\epsilon_{p c}}{N_{p c}}\right]
$$

\section{Optimization and the Design Methodology}

In this study, numerical optimization is used to design cooling jackets which minimize coolant flow rate. A brief description of the mathematical formulation of a general optimization problem is given followed by a description specific to cooling-jacket design.

\section{General Form of Optimization Problems}

A number of parameters describes the design of a system being optimized. Some of these parameters are fixed during the design optimization (fixed parameters) and others, the design variables (denoted by the vector $\mathbf{X}$ ), are varied within limits (side constraints) to determine the best design. The goal of the optimization is to minimize the value of an objective function $(F(\mathbf{X}))$. There can also be a set of constraint functions $(\mathbf{G}(\mathbf{X}))$ which satisfy a set of relations for the design to be satisfactory (feasible). When $\mathbf{G}(\mathbf{X})$ is equal to one of the limiting values, it is denoted as active. Mathematically, the optimization problem is posed as

$$
\begin{aligned}
& \underset{\mathbf{X}}{\min } F(\mathbf{X}) \\
& \mathbf{X}_{\mathbf{l}}<\mathbf{X}<\mathbf{X}_{\mathbf{u}} \\
& \mathbf{G}_{\mathbf{l}}<\mathbf{G}(\mathbf{X})<\mathbf{G}_{\mathbf{u}}
\end{aligned}
$$

where $(25)$ is read as "find the minimum of $F(\mathbf{X})$ over the range of $X^{n},(26)$ is an inequality that gives side constraints on $X$, and (27) is an inequality that defines the behavior constraints on the problem.

There are a number of numerical optimization routines available to solve problems described by (25) through (27). The software utilized in this study is the Sizing and Optimization Language (SOL, ref. 16) which incorporates the ADS optimization routine (ref. 17). SOL is a high level computer language which simplifies the application of optimization for many problems. A simple example of using SOL's optimization capability is given in Appendix B. 


\section{Cooling-Jacket Optimization}

Table 1 summarizes the parameters used in the cooling. jacket optimization procedure. For all cases considered in this study, the required coolant flow rate $(\dot{m})$ is the objective function. The objective function is somewhat unusual because it is one of the design variables. This choice of objective function is allowed since it is just a simple form of $F(\mathbf{X})$ in (25). The design variables, shown in table 1 , are the coolant flow rate as mentioned above, the cooling-jacket inlet pressure $\left(p_{\text {in }}\right)$, and a number of geometry parameters that are defined in figure 2. The constraints, also shown in table 1, are similiar for both channel-fin and pin-fin cooling jackets, however, the computational details differ. The position of maximum cooling-jacket temperature $\left(T_{\text {outer }}\right)$ is shown in figure 3 for both cooling-jacket geometries. Actually, the locations in figure 3 for maximum temperature in the outer wall are strictly correct only for low thermal conductivity cooling-jacket materials. For high conductivity materials, two-dimensional thermal models show the peak temperature location to be on the outer wall surface away from the channel wall or pin. However, surface temperature variations are small so the surface location for determining peak temperature when using high conductivity materials is not critical. As defined in (24), $N_{f}$ applies to fatigue life of the outer wall. The stress constraints in table 1 are derived from $\sigma_{w}$ and $\sigma_{b}$ (given by (10) and (11)) for channel-fin geometries and $\sigma_{p}$, $\sigma_{\text {outer }}$, and $\sigma_{\text {inner }}$ (given by (12), (13), and (14)) for pin-fin geometries. The Mach-number and pressure constraint functions in table 1 are evaluated at the panel exit for both pin-fin and channel-fin cooling jackets. The limiting values given in table 1 for $p_{\text {ulim }}, T_{\mathrm{lim}}, p_{\mathrm{lim}}, M_{\mathrm{lim}}, N_{f, \mathrm{lim}}$, and $\sigma_{\mathrm{lim}}\left(T_{\text {outer }}\right)$ are described in the next section.

The ADS optimization option used in this study is the modified feasible direction method described in reference 18 . Finite difference derivatives of the constraint functions are used in all cases. All the analyses described in the analytical basis section are repeated for constraint evaluation whenever any design variable changed. No attempt is made to improve numerical efficiency by using knowledge of the dependency of the constraint functions on the design variables.

\section{Optimization Results and Parameter Studies}

The cooling-jacket optimization methodology is applied first to a single cooled panel (fig. 3) and then to a simple three-panel simulated engine. The purpose of the single panel studies is to demonstrate and apply the methodology to a simple case in order to understand the interaction of the design variables and behavior constraints and their effect on the objective function over a range of conditions. The single panel studies compare optimum designs utilizing two types of cooling-jacket construction (channel and pin fin), three different materials, and different levels of heat flux and coolant inlet pressure limit $\left(p_{\text {ulim }}\right)$. The purpose of the three-panel study is to demonstrate use of the methodology to investigate flow routing effects. Only a single cooling-jacket material and geometry (nickel channel fin) with fixed heat fluxes (150 Btu/ $\mathrm{ft}^{2}$-sec for the 36 -inch-long inlet, $2000 \mathrm{Btu} / \mathrm{ft}^{2}$-sec for the 24-inch-long combustor, and $300 \mathrm{Btu} / \mathrm{ft}^{2}$-sec for the 36 -inch-long nozzle) are considered for the three-panel study.

All the panels are 36 inches wide with lengths (in the flow direction) of 24 and 36 inches. The heat flux $(q)$ is assumed uniform over a single panel, however, the design method can utilize heat fluxes variable along the length of a panel. In the parameter studies, cooling-jacket panels are optimized with $q$ varying from 200 to $2000 \mathrm{Btu} / \mathrm{ft}^{2}$-sec. The hydrogen inlet temperature $\left(T_{\text {in }}\right)$ is assumed to be $100^{\circ} \mathrm{R}$ in all cases. The inlet pressure $\left(p_{\text {in }}\right)$ is a design variable with an upper limit $\left(p_{u l i m}\right)$ that varies between 1200 and 5000 psi in the parameter studies. The panel outlet pressure limit $\left(p_{\text {lim }}\right)$, the coolant Mach limit $\left(M_{\text {lim }}\right)$, and the fatigue limit $\left(N_{f, \text { lim }}\right)$ have nominal values of $600 \mathrm{psi}, 0.25$, and 600 cycles, respectively. The stress limits $\left(\sigma_{\text {lim }}\left(T_{\text {outer }}\right)\right)$ are the lesser of the temperature dependent yield and 100 hour creep rupture strengths.

Three candidate materials are used in the studies. The three materials (Nickel 201, zirconium copper, and titanium aluminide) offer a range of the important material properties such as thermal conductivity, high temperature capability, and strength. Typical properties of the candidate alloys are shown in table 2 , and a brief discussion of each follows.

Nickel 201 (references 13 and 19) offers moderate thermal conductivity and higher temperature capability $\left(1540^{\circ} \mathrm{F}\right)$ than the other alloys studied. These properties along with high ductility for fatigue resistance make nickel an attractive choice for a cooling jacket.

Zirconium Copper (CDA 150, references 20 and 21) is a high temperature copper alloy which has excellent thermal conductivity. It has the lowest temperature limit of the candidate alloys $\left(1000^{\circ} \mathrm{F}\right)$. Copper alloys are used in high heat flux regions of the Space Shuttle main engine, and their applicability to scramjet engines is of interest.

Titanium Aluminides (reference 22) are a new family of materials which offer the high specific strength of titanium with higher temperature capabilities. Their low density, although not considered in this analysis, makes them attractive for flight vehicles. Some deficiencies in these materials are their low thermal conductivity, low ductility, and questionable hydrogen compatibility.

\section{Single-Panel Studies}

In this section, results for optimization of single coolingjacket panels are given, followed by results for the three-panel simulated engine flow routing study. All results are optimum designs for the given fixed parameters.

In figure 4 , the minimum required coolant flow rate for a single nickel channel-fin panel is shown as a function of incident heat flux. The results are for a 36 -inch by 36 -inch panel with a $5000 \mathrm{psi}$ inlet pressure limit. Also shown on the figure is a linear extrapolation of the required flow rate for the lowest heat flux $\left(200 \mathrm{Btu} / \mathrm{ft}^{2}-\mathrm{sec}\right)$. The linear extrapolation is the required coolant flow rate that a simple energy balance (i.e. temperature rise proportional to the heat rate and inversely proportional to the flow rate, with the flow rate determined by a maximum coolant temperature) might predict and indicates that a simple energy balance underpredicts coolant requirements at higher heat fluxes. In the optimum design results of figure 4 , the constraints which affect the flow rate change with the heat flux level. The constraints active at the $200 \mathrm{Btu} / \mathrm{ft}^{2}$-sec heat flux are the cooling-jacket temperature and stress limits. At $1000 \mathrm{Btu} / \mathrm{ft}^{2}-\mathrm{sec}$, the active design constraints change to include the coolant Mach constraint. The set of active design constraints at $2000 \mathrm{Btu} / \mathrm{ft}^{2}$-sec no longer includes the peak metal temperature constraint because the fatigue-life constraint is now active. The fatigue life constaint depends on the temperature difference through the cooling jacket as well as the peak metal temperature. Although smooth curves are faired through the calculated points of this and the following figures, the actual curves undoubtedly contain slope discontinuities whenever the set of 
active design constraints change.

Figure 5 shows the optimum required coolant flow rate for a nickel channel-fin panel as a function of the inlet pressure limit at three heat flux levels. Also included on the figure are the flow passage geometries for the optimum designs. As seen in the figure, the channel width design variable $(s)$ is at its lower limit (0.015 in.) for the optimum design in all cases. Table 3 summarizes the active design constraints for the cases shown in figure 5. At the two lower heat flux levels, there is little change in the optimum coolant requirement with pressure limit variation. Comparisons of figure 5 with table 3 indicate that the only time there is a large change in coolant requirement with pressure variations is when the fatigue-life and Mach-number constraints are both active. Thus, it can be inferred that the large increase in coolant flow requirement with reduced pressure results from an interaction of these two constraints. The cause of the interaction merits some explanation. With the coolingjacket geometry and coolant flow rate assumed fixed, as inlet pressure limit decreases the pressure along the length of the jacket also decreases. As pressure decreases, the temperature of the hydrogen along the length of the passage is not appreciably affected because of the small pressure dependence of the temperature-enthalpy relation (eqn. 2). Decreasing coolant pressure at constant temperature implies a density decrease, so velocity of the coolant must increase to maintain the fixed mass flow rate. The increased velocity corresponds to an increase in coolant Mach number for the above assumptions, however, an increase in Mach number is not allowed since the Mach constraint is active. Therefore, the geometry is changed. Channel height increases to enforce the Mach constraint. The increase in channel height reduces the convective film coefficient (as can be derived using eq. 8) which increases the temperature difference through the cooling jacket. An increased temperature difference results in the violation of the active fatigue constraint, so the coolant flow rate must be increased to provide higher film coefficients and reduce the temperature difference through the cooling jacket. Of course, these geometry and flow rate changes affect the pressure and temperature of the coolant, and the process just described repeats until further changes are not needed. The large increase in coolant flow rate caused by the strong coupling of the coolant Mach and cooling-jacket fatigue constraints was not foreseen before the study began but was revealed by the cooling-jacket design methodology.

Sensitivity of the optimum coolant flow rate to the active constraint limits at $q=2000 \mathrm{Btu} / \mathrm{ft}^{2}$-sec with $p_{\text {in }}=3000 \mathrm{psi}$ is shown in figure 6 with the nominal flow rate given in figure 5. The active constraints are bending stress due to internal pressure along with the fatigue and Mach constraints. It is apparent that the fatigue life requirement is the most influential constraint. Also, since the Mach-number constraint is somewhat arbitrary (provided it has a low subsonic value), the figure shows the level of the gains possible by relaxing this constraint.

Figure 7 illustrates the optimum coolant flow for channelfin and pin-fin jackets using nickel as the jacket material and $3000 \mathrm{psi}$ as the inlet pressure limit. At the lower heat-flux levels, there is little difference in the value of the optimum coolant flow rate for channel and pin fins. At high heat fluxes, the channel fins have lower coolant flow requirements than the pin fins. This behavior results because pin-fin jackets have smaller minimum flow areas than channel-fin jackets in comparable designs due to the three-dimensional geometry of the pin fin. The small flow area magnifies the effect the Machnumber constraint has on coolant requirements, especially when the Mach and the fatigue-life constraints interact. Also, for the pin-fin cooling jacket results in this figure, the designs are not constrained by strength requirements and the fatiguelife constraint becomes active at lower heating loads than for comparable channel-fin jackets.

An additional objective of this study is to compare the performance of candidate cooling-jacket materials. In addition to the nickel material already mentioned, cooling jackets constructed of a copper allcy and titanium aluminide are also investigated. Figure 8 compares the performance of channelfin cooling jackets for the three materials over a range of heat-flux conditions. The nickel cooling jacket exhibits the best performance (lowest optimum coolant flow requirement) over the entire heat-flux range due to its high allowable temperature (see table 2). As in previous cases, the fatigue limit is an active design constraint for nickel jackets at high heat fluxes. However, fatigue is never an active design constraint for the copper or titanium cases in this study. Neither the copper alloy nor the titanium aluminide strain inelastically after the first cycle due to the high thermal conductivity for copper and the high yield strength for the titanium. Also, the copper and the titanium aluminide alloy cooling jackets are always at their temperature limit while the nickel panels are below their temperature limit at higher heat fluxes because of the fatigue-life constraint. The pin-fin jacket geometry yields similiar behaviors for these materials (figure 9) except that nickel is no longer the best material at high heat fluxes. The extreme sensitivity of the pin-fin geometry to the fatigue-life and coolant Mach-number constraint interaction cause the nickel pin-fin cooling jacket to require larger coolant flow rates at high heat fluxes than either the copper or the titanium jackets which have no fatigue problem.

\section{Flow-Routing Study for Three-Panel Model}

The design of the cooling system for an entire scramjet engine requires the simultaneous design of a system of coolingjacket panels and the consideration of many flight conditions. Many schemes for routing the flow through the panels are possible, and the design methodology described in this paper is applicable for any given routing scheme. Three panels with nickel channel-fin cooling jackets simulating a scramjet cooling system are analyzed for a single flight condition to evaluate the merits of three flow routing schemes. The optimum total flow rates for each scheme are compared in figure 10. The scheme with independent coolant flow for each panel requires the least total flow of coolant. However, independently cooled panels may give large temperature gradients in the coolant flow direction. These temperature gradients may induce unacceptable thermal stresses in the engine structure. Although the primary structure thermal stresses are not a constraint in this study, two other flow routing schemes which should reduce these thermal stresses are considered.

The inlet-to-nozzle and the nozzle-to-inlet flow routings shown on figure 10 are a series connection of panels where the outlet of one panel goes to the inlet of the next. The inlet-tonozzle flow routing requires only 4 percent more coolant but the nozzle-to-inlet routing requires over 17 percent more coolant than the individually cooled panels. By examining the behavior constraints active for these designs, the reasons for the differences are apparent. The active constraints are the cooling-jacket fatigue and coolant Mach constraints for the combustor (center) panel. In the nozzle-to-inlet flow routing 
case, the coolant flow entering the combustor is at a higher temperature and a lower pressure than for the inlet-to-nozzle routing case. These conditions require a larger coolant flow rate to satisfy the constraints in the combustor. Similar effects are seen in the single panel cases for reduced inlet prissure at a high heat flux level.

\section{Observations on the Optimization Design Methodology.}

The scramjet cooling-jacket design methodology developed and applied in this study has proven to be very useful for gaining insight of the important design requirements and constraints driving the optimum design. Since the result of every successful application of the methodology is a feasible design with minimized coolant flow rate, a study which varies the fixed parameters determines the coupled sensitivity of the optimum design to these parameters. Simple sensitivities determined from conventional parameter studies may not correspond to feasible designs since some constraints may be neglected. An implication of this observation is that the behavior and side constraint limits must be carefully chosen since the optimum coolant flow rate may be appreciably increased for unduly restrictive limits. An additional advantage of the methodology is that unforseen coupling of the design constraints and unanticipated effects of parameter changes can be uncovered as was the case for the coupling of the coolant Mach number and fatigue life constraints for nickel cooling jackets.

No detailed measurements of the computational efficiency of the method have been made. However, the computational time has been reasonably short for single panel optimizations. The computation time increases drastically for multiple panel cases. As noted earlier, a brute force approach is used which repeats the analysis of all the cooling-jacket panels for any change in the design variables. A more selective use of the analysis would be beneficial for multiple panel cases. Finally, the use of the Sizing and Optimization Language to describe the optimization problem simpifies the coding of the optimization problem and aids in interpretation of the optimization results.

\section{Concluding Remarks}

This paper describes a methodology for design of metallic cooling jackets for scramjet engines. The engine cooling jackets use the hydrogen fuel as a coolant and are designed using the numerical optimization routine ADS included in a new computer language, the Sizing and Optimization Language (SOL). The optimization goal is to design cooling jackets which minimize the required coolant. The designs also satisfy constraints on cooling-jacket temperatures, mechanical stresses, and fatigue life, and on coolant Mach number and pressure drop with various limits on cooling-jacket geometry. The method is applied to channel-fin and pin-fin cooling jackets. The analytical methods for predicting cooling-jacket performance and the incorporation of the analysis into constraint functions are also explained.

Results of optimization of cooling-jacket designs for single cooled panels are presented. The results show the inadequacy of a simple energy balance for determining coolant requirements. The capability of optimization to uncover the coupling of seemingly disparate constraints is found to give new insight in the design process. For example, the coolant Mach and cooling-jacket fatigue constraints, which at first seemed unrelated, are found to be coupled by the design methodology. The capability to perform parametric sensitivity analyses by simply executing the model with various constraint limits is also demonstrated. Comparisons are made between pin-fin and channel-fin cooling jackets which show the channel-fin jacket generally superior for the conditions investigated. The comparison of copper and titanium alloys to nickel for a cooling-jacket material favor nickel due to its high temperature capability, moderate thermal conductivity, and high ductility.

The optimization of the cooling-jacket panels in the flow routing study of three panels representing a scramjet engine indicates that independently cooled panels require the least coolant. If thermal stresses in the engine primary structure require flow to be routed through a series of panels, an inletto-nozzle routing results in lower optimum coolant flow rates than a nozzle-to-inlet scheme. This result is explained in terms of the active constaints and the single panel studies.

The design methodology has the capability to be applied to more complicated design problems than those illustrated in this study but care must be taken that the computer time does not become unreasonable.

\section{References}

${ }^{1}$ Shore, C. P., "Review of Convectively Cooled Structures for Hypersonic Flight," NASA TM87740, May, 1986.

${ }^{2}$ Wieting, A. R. and Guy, R. W., "Thermal Structural Design of an Airframe-Integrated Hydrogen-Cooled Scramjet," Journal Of Aircraft, Vol 13, No. 3, March 1976, pp. 192-197.

${ }^{3}$ Fowler, J. R., "GASPLUS User's Manual, Version 2.2", Sverdrup Technology, Inc., Distributed by authority of the NASP Joint Program Office, Wright-Patterson AFB, Ohio.

${ }^{4}$ Kays, W. M., and London, A. L., Compact Heat Exchangers, 2nd ed., McGraw-Hill, New York, 1965.

${ }^{5}$ Metzger, D. E., Fan, Z. X., and Shephard, W. B., "Pressure Loss and Heat Transfer Through Multiple Rows of Short Pin Fins," ASME Paper No. 82-IHTC- 31, Sept. 1982.

${ }^{6}$ Arora, S. C. and Abdel Messah, W., "Pressure Drop and Heat Transfer Characteristics of Circular and Oblong Low Aspect Ratio Pin Fins," Heat Transfer and Cooling in Gas Turbines, AGARD Conference Proceeding No. 390, pp. 4-1 -4-15, May 1985.

${ }^{7}$ Taylor, M. F., "Correlation of Local Heat Transfer Coefficients for Single-Phase Turbulent Flow of Hydrogen in Tubes With Temperature Ratios to 23," NASA TN D-4332, 1968.

${ }^{8}$ VanFossen, G. J., "Heat Transfer Coefficients for Staggered Arrays of Short Pin Fins," ASME Journal of Engineering for Power, Vol. 104, April 1982, pp. 268-274.

${ }^{9}$ Brigham, B. A. and VanFossen, G. J., "Length to Diameter and Row Number Effects in Short Pin Fin Heat Transfer," ASME Journal of Engineering for Gas Turbines and Power, Vol. 106, Jan. 1984, pp. 241-245.

${ }^{10}$ Metzger, D. E. and Haley, S. W., "Heat Transfer Experiments and Flow Visualization for Arrays of Short Pin Fins," ASME Paper No. 82-GT-138, April 1982. 
${ }^{11}$ Metzger, D. E., Berry, R. A., and Bronson, J. P., “Developing Heat Transfer in Ducts With Staggered Arrays of Short Pin Fins," ASME Journal of Engineering for Power, Vol 104, April 1982, pp. 701-706.

${ }^{12}$ Roark, R. J., Formulas for Stress and Strain, 5th ed., McGraw-Hill, New York, 1975. p. 342.

${ }^{13}$ Manson, S. S., "The Challenge to Unify Treatment of High Temperature Fatigue - A Partison Proposal Based on Strainrange Partitioning," Fatigue at Elevated Temperatures, ASTM STP 520, American Society For Testing and Materials, Philadelphia, 1973, pp. 744-782.

${ }^{14}$ Buchmann, O. A., et. al., "Advanced Fabrication Techniques for Hydrogen Cooled Engine Structures," NASA CR 3949, November, 1985.

${ }^{15}$ Halford, G. R., Saltsman, J. F., and Hirschberg, M.H., "Ductility Normalized-Strainrange Partitioning Life Relations for Creep-Fatigue Life Prediction," Proceedings of the Conference on Environmental Degradation of Engineering Materials. Virginia Tech Printing Dept., Blacksburg, VA 1977, pp. 599-612.

${ }^{16}$ Lucas, S. H., and Scotti, S. J., "The Sizing and Optimization Language - A Computer Language for Design Problems," NASA TM 100565, April, 1988.

${ }^{17}$ Vanderplaats, G. N., "ADS - A Fortran Program for Automated Design Synthesis, Version 1.10," NASA CR 177985, September 1985.

${ }^{18}$ Vanderplaats, G. N., "A Robust Feasible Directions Algorithm for Design Synthesis," AIAA Paper 83-938, May, 1983.

19 "Huntington Nickel Alloys," Huntington Alloy Products Division, The International Nickel Company, Inc., Huntington, West Virginia.

${ }^{20}$ Cronin, J. J., "Selecting High Conductivity Copper Alloys for Elevated Temperature Use," Metals Engineering Quarterly, August 1976, pp. 222-230.

${ }^{21}$ Advisory Group For Aerospace Research and Development (AGARD), Characterization of Low Cycle High Temperature Fatigue by the Strainrange Partitioning Method. AGARD Conference Proceedings No. 243, North Atlantic Treaty Organization, April, 1978.

${ }^{22}$ Blackburn, M. J. and Smith, M. P. "R\&D on Composition and Processing of Titanium Aluminide Alloys for Turbine Engines," Technical Report AFWAL-TR- 82-4086, July 1982.

\section{Appendix A - Pressure Mapping}

One of the problems that exists with the pressure drop calculation (eqn. 3) is that negative pressures may occur in the flow model during the optimization process. The negative pressures result from flow rate determining pressure drop in our models while physically pressure drop determines flow rate. Besides being unrealistic, the negative pressures cause errors in the gas property routines. This problem is avoided by smoothly mapping pressures which fall below a preset limit value to a positive pressure during the optimization process.
Since this limit value is set below the minimum exit pressure limit for the panel, the optimization procedure can continue calculations with negative pressures without affecting the final solution. The mapping for pressure drop has two forms depending on the value of the pressure of the coolant entering the segment. If pressure of coolant entering the segment $\left(p_{i}\right)$ is above the limiting pressure ( $\left.p_{\text {limit }}\right)$, the mapped exiting pressure is

$$
p_{i+1, \text { map }}=-\frac{\left(p_{\text {limit }}-p_{\text {min }}\right)^{2}}{p_{i+1}-2 p_{\text {limit }} p_{\min }}+p_{\text {min }}
$$

where $p_{i+1}$ is the exit pressure of a segment computed from (3) and $p_{\min }$ is the lower limit of the mapped pressures. When the pressure of the coolant entering the segment is below plimit, then the equation for the mapped pressure is

$$
p_{i+1, \text { map }}=\frac{1}{\frac{1}{p_{i}-p_{\text {min }}}+\frac{p_{i}-p_{i+1}}{\left(p_{\text {limit }}-p_{\min }\right)^{2}}}+p_{\text {min }} \text {. }
$$

In this study, $p_{\text {limit }}$ is set to 400 psi and $p_{\min }$ is set to 300 psi.

\section{Appendix B - Overview of SOL}

SOL is a special-purpose computer language geared towards optimization (ref. 16). SOL simplifies the application of numerical optimization methods with a syntax and error-checking capability developed for optimization problems. SOL is currently available for VAX/VMS systems.

Using SOL as a tool for engineering design involves writing computer codes in SOL that apply numerical optimization methods to a design problem. SOL offers many features found in conventional languages (e.g. FORTRAN or Pascal) including: variables; math operators such as addition; built-in math functions like square root; DO loops; IF statements; subroutines; and statements to allow the output of values. Further, SOL incorporates the methods of numerical optimization implemented in the ADS optimization routine (ref. 17) and other unique features. An optimization problem can be described in SOL in a manner similiar to the way the problem is posed mathematically. In this sense, SOL can be called "nat-

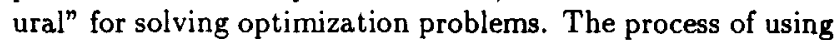
SOL is shown in figure Bl. A SOL program is written and then passed as input to the SOL compiler that translates the SOL program into an equivalent FORTRAN program. The resulting FORTRAN program is eventually executed to solve the design problem. SOL allows the description of an optimization problem with a high-level language feature called the "OPTIMIZE statement." The description of an optimization problem with SOL's OPTIMIZE statement closely parallels the mathematical description of the problem, as illustrated in figure $\mathrm{B} 2$. The example problem is to minimize an objective function of two bounded design variables with a single constraint relation. Mathematically, the problem is expressed as "minimize $f$ unct $(x, y)$, where $x$ and $y$ are the design variables." The bounds on the design variables and the constraint relations are given under the heading, "Subject to." The single constraint relation is stated by the line, "constraint $(x, y)=5$." Finally the equations that define the objective and constraint functions in terms of the design variables are given.

SOL expresses the optimization problem in much the same way. The program begins with the word "PROGRAM" followed by the name of the program. The optimization problem is posed by an OPTIMIZE statement. The objective 
function is declared by a single variable given after the word "OPTIMIZE." Next, the design variables and constraint relations appear between the words "USE" and "END USE." The lower and upper bounds on the design variables appear enclosed by brackets. In addition, an initial value is required for each design variable to give the optimization software a starting point. The constraint function is represented by the single variable, "constraint," which appears in a constraint relation. Any variable names can be used to represent the objective and constraint functions. Finally, between the words "END USE" and "END OPTIMIZE," equations are given which describe the objective and constraints as functions of the design variables. Although this example shows mathematical equations for the objective and constraint functions, the OPTIMIZE statement is not limited to using equations. Any valid SOL statements, such as subroutine calls, IF statements, even other OPTIMIZE statements, could be used to define the objective and constraint functions. The OPTIMIZE statement ends with the words "END OPTIMIZE," and then the SOL program ends with the word "END" followed by the program name.

In the present study, a SOL program describes the cooling-jacket design problem. Existing FORTRAN routines do most of the calculations for the optimization constraints. Although these constraint calculation routines can be written in SOL, it is more efficient to separate the analysis routines from the description of the design problem. Also, since several of the routines are available in FORTRAN, duplication of the coding effort would be wasteful. SOL's "FORTRAN block" feature, which allows existing FORTRAN routines to be called from within a SOL program with communication via parameter passing, is used to incorporate the constraint analysis routines.

SOL offers another important feature in the error-checking capability of its compiler. The SOL compiler checks a SOL program for a variety of errors, such as the use of an uninitialized variable in an equation, or the alteration of an optimization design variable by statements inside an OPTIMIZE statement. The compiler does not have "artificial intelligence"; it cannot tell if a problem is formulated correctly. However, it does catch a variety of errors, which can be difficult to find otherwise. In addition, the SOL compiler can produce a program listing that is useful when debugging SOL programs.

\begin{tabular}{|c|c|c|c|}
\hline & Nickel 201 & $\begin{array}{l}\text { Zirconium } \\
\text { copper }\end{array}$ & $\begin{array}{l}\text { Titanium } \\
\text { aluminide }\end{array}$ \\
\hline Temperature limit & $1540^{\circ} \mathrm{F}$ & $1000^{\circ} \mathrm{F}$ & $1400^{\circ} \mathrm{F}$ \\
\hline $\begin{array}{l}\text { Thermal conductivity } \\
\text { (Btuh - hPF) }\end{array}$ & 35 & 200 & 8 \\
\hline Elastic modulus (psi) & $30 \times 10^{6}$ & $16.5 \times 10^{6}$ & $18 \times 10^{6}$ \\
\hline $\begin{array}{l}\text { Coefficient of thermal } \\
\text { expansion (in. } / \text { in. }{ }^{\circ} \mathrm{F} \text { ) }\end{array}$ & $8.5 \times 10^{-6}$ & $9.8 \times 10^{-6}$ & $6.0 \times 10^{-6}$ \\
\hline Density ( $\left(b / i^{3}{ }^{3}\right.$ ) & .321 & .323 & .165 \\
\hline $\begin{array}{l}\text { Limit stress at } \\
\text { maximum temperature } \\
\text { (psi) }\end{array}$ & 8,000 & 7,000 & 30,000 \\
\hline
\end{tabular}

Table 2 - Cooling jacket material properties

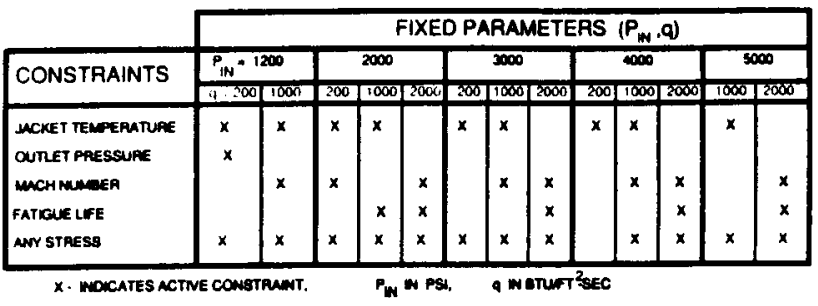

Table 3 - Active constraints corresponding to nickel channel designs in figure 5

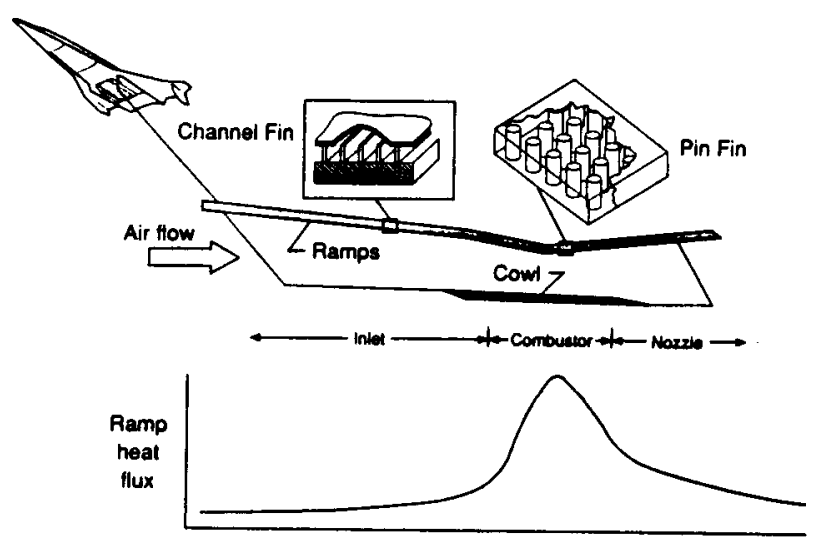

Figure 1 - Schematic of scramjet engine with typical heat fluxes

\begin{tabular}{|c|c|c|c|}
\hline & & CHANNEL FIN & PIN FIN \\
\hline $\begin{array}{l}\text { OBJECTIVE } \\
\text { FUNCTION }\end{array}$ & Mass Flow Rate & $\dot{m}$ & $\dot{\boldsymbol{m}}$ \\
\hline $\begin{array}{c}\text { DESIGN } \\
\text { VARIABLES* }\end{array}$ & $\begin{array}{l}\text { Mass Flow Rate } \\
\text { Inlet Pressure } \\
\text { Aspect Ratio } \\
\text { Spacing } \\
\text { Outer Wall Thickness } \\
\text { Channel Wall Thickness } \\
\text { Pin Diameter } \\
\text { Fillet Radius** } \\
\end{array}$ & $\begin{array}{c}\dot{m}(\dot{m}>0.0) \\
p_{\text {in }}\left(p_{\text {in }}<p_{\text {ulim }}\right) \\
h / s(0.5<h / s<4.0) \\
s(s>.015 \mathrm{in}) \\
t(t>.005 \mathrm{in}) \\
w(w>.005 \mathrm{in}) \\
- \\
-\end{array}$ & $\begin{array}{c}\dot{m}(\dot{m}>0.0) \\
p_{\text {in }}\left(p_{\text {in }}<p_{\text {ulim }}\right) \\
h / d(0.2<h / d<6.0) \\
s(d>d+2 r+0.005 \text { in }) \\
t(t>.005 \text { in }) \\
- \\
d(d>0.0) \\
r / h(.005<r / h<1)\end{array}$ \\
\hline CONSTRAINTS & $\begin{array}{l}\text { Jacket Temperature } \\
\text { Outlet Pressure } \\
\text { Mach Nurnber } \\
\text { Fatigue Life } \\
\text { Stress } \\
\text { Stress } \\
\text { Stress } \\
\end{array}$ & $\begin{array}{c}T_{\text {ou toe }}<T_{\text {lim }} \\
P_{\text {out }}>\text { Plim } \\
M<M_{\text {lim }} \\
N_{J}>N_{\text {f.llm }} \\
\sigma_{b} /\left(\sigma_{\text {lim }}\left(T_{\text {oukr }}\right)\right)<1.0 \\
\sigma_{\infty} /\left(\sigma_{\text {lime }}\left(T_{\text {outer }}\right)\right)<1.0 \\
-\end{array}$ & $\begin{array}{c}T_{\text {outer }}<T_{\text {lim }} \\
p_{\text {out }}>p_{\text {lim }} \\
M<M_{\text {lim }} \\
N,>N_{\text {flim }} \\
\left.N_{\text {lim }}\right)<1.0 \\
\sigma_{\text {outer }} /\left(\sigma_{\text {lim }}\left(T_{\text {outer }}\right)\right)<1.0 \\
\sigma_{\text {igser }} /\left(\sigma_{\text {lim }}\left(T_{\text {outer }}\right)\right)<1.0 \\
\sigma_{\mathrm{p}} /\left(\sigma_{\text {lim }}\left(T_{\text {outer }}\right)\right)<1.0\end{array}$ \\
\hline
\end{tabular}

Table 1 - Optimization parameters in cooling jacket design 


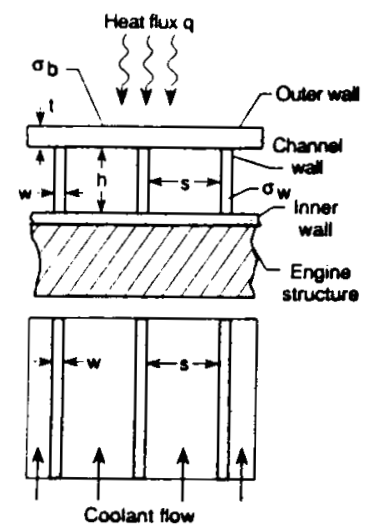

Channel fin cooling jacket

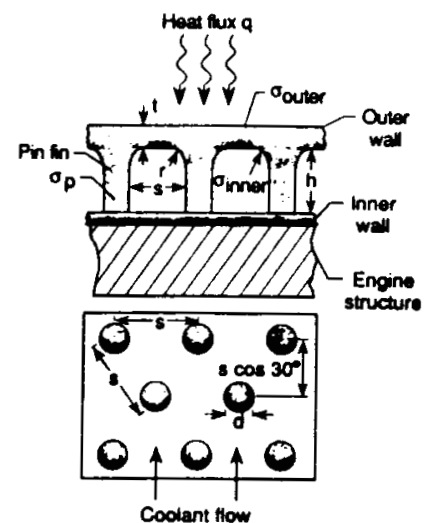

Pin fin cooling jacket

Figure 2 - Characteristic dimensions for cooling jackets
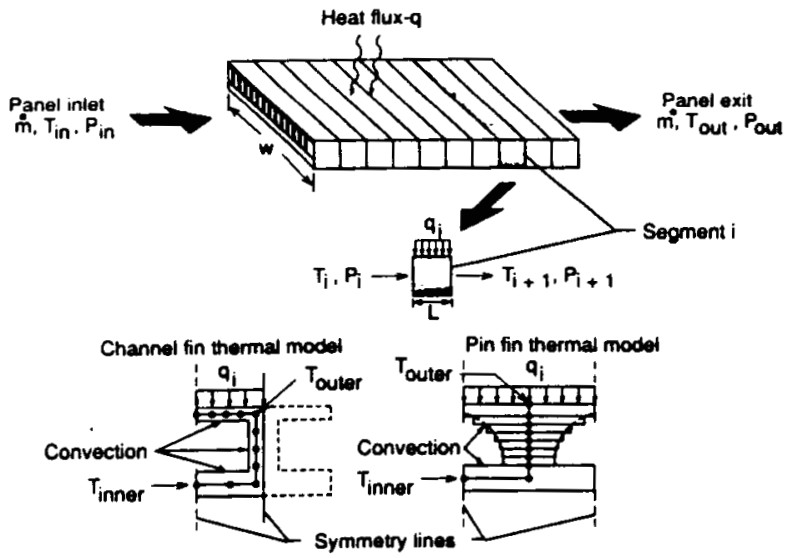

Figure 3 - Cooling jacket flow and thermal models

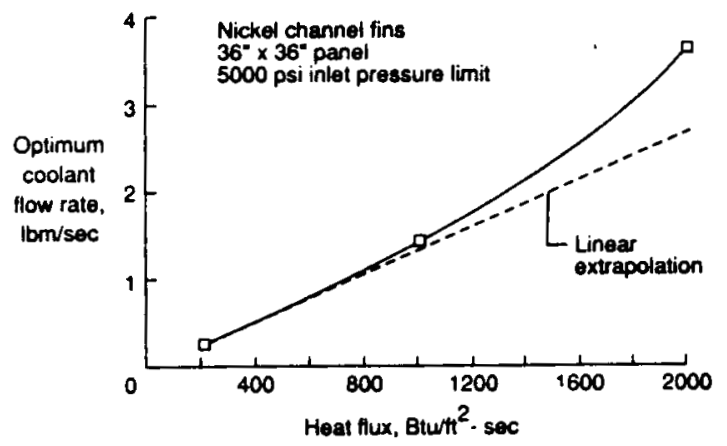

Figure 4- Effect of heat flux on optimum coolant flow rates for nickel channel fin cooling jackets

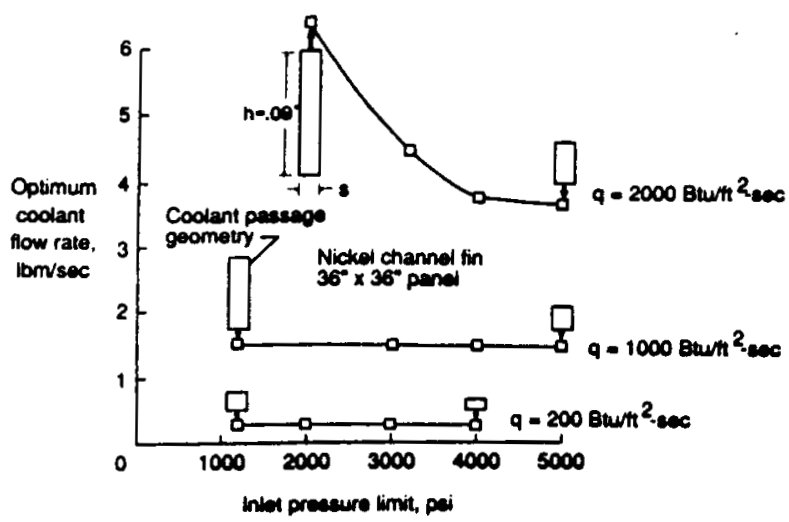

Figure 5 - Effect of inlet pressure limit on optimum coolant flow rates for nickel channel fin cooling jackets at various incident heat fluxes

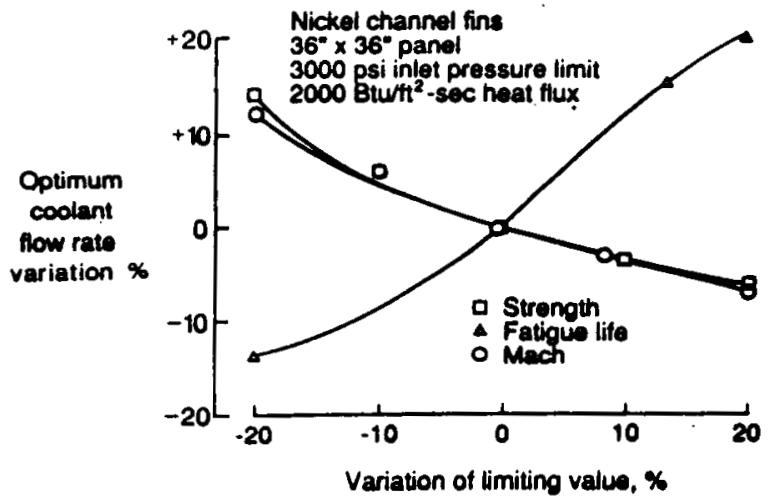

Figure 6 - Sensitivity of optimum coolant flow rate to limiting values of strength, fatigue life, and Mach constraints

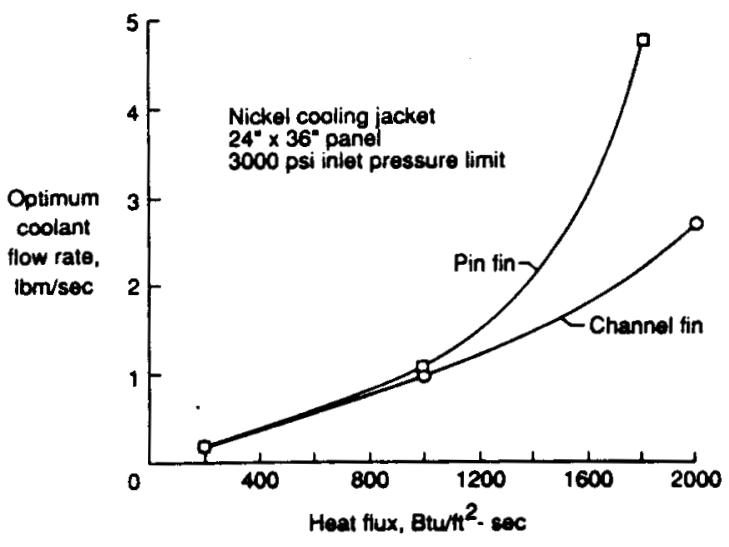

Figure 7 - Variation of optimum coolant flow rate with heat flux for nickel channel fin and pin fin cooling jackets 


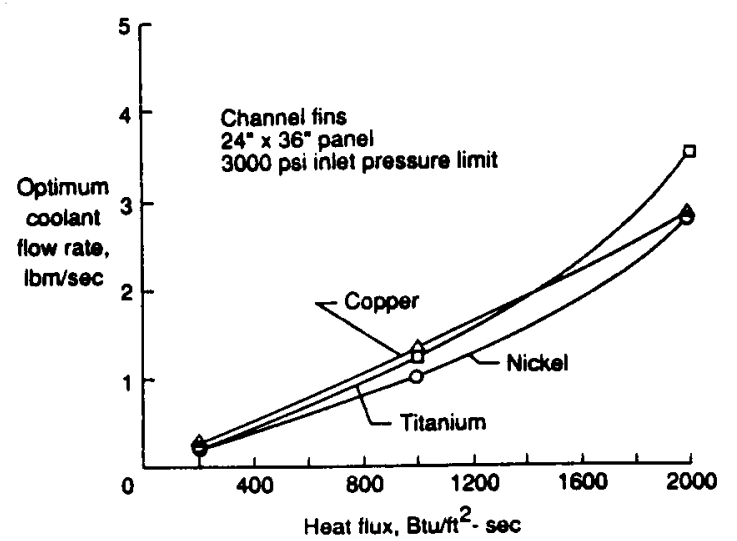

Figure 8 - Variation of optimum coolant flow rate with heat flux for nickel, copper, and titanium channel fin cooling jackets

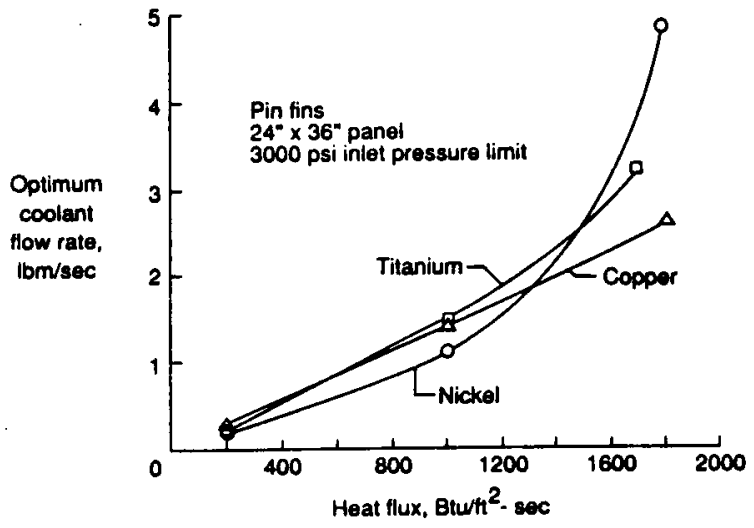

Figure 9 - Variation of optimum coolant flow rate with heat flux for nickel, copper, and titanium pin fin cooling jackets

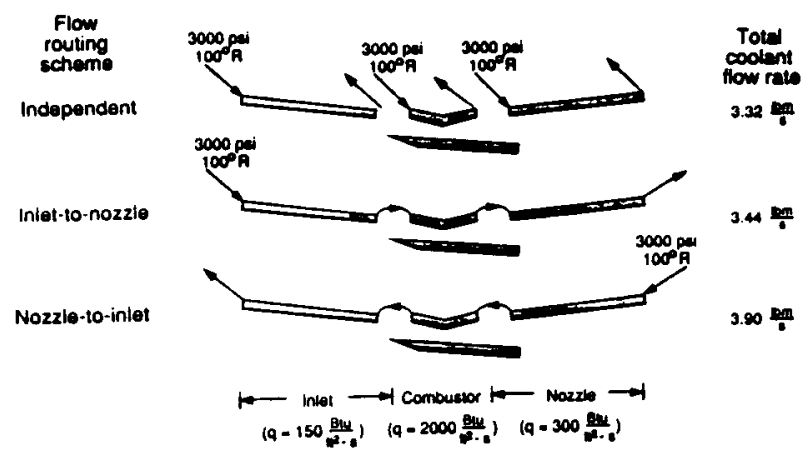

Figure 10 - Comparison of optimum coolant requirements for three coolant flow routing schemes
ORIGINAL PAGE IS

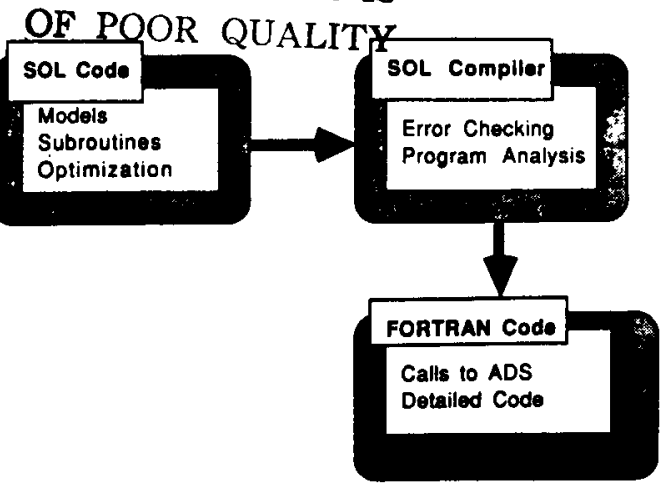

Figure B1 - Schematic of using Sizing and Optimization Language to solve an optimization problem

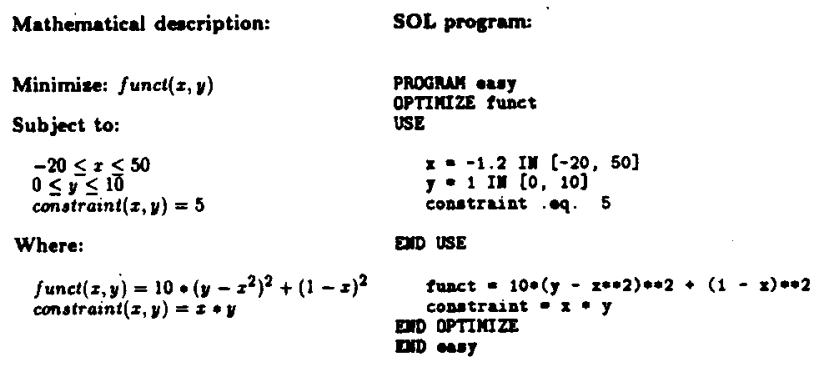

Figure B2 - Formulation of an optimization problem using SOL 
Standard Bibliographic Page

\begin{tabular}{|c|c|c|}
\hline $\begin{array}{l}\text { 1. Report No. } \\
\text { NASA TM-100581 }\end{array}$ & 2. Government Accession No. & 3. Recipient's Catalog No. \\
\hline \multicolumn{2}{|l|}{ 4. Title and Subtitle } & 5. Report Date \\
\hline \multirow{2}{*}{\multicolumn{2}{|c|}{$\begin{array}{l}\text { Active Cooling Design for Scramjet Engines Using } \\
\text { Optimization Methods }\end{array}$}} & March 1988 \\
\hline & & 6. Performing Organization Code \\
\hline \multicolumn{2}{|c|}{$\begin{array}{l}\text { 7. Author(s) } \\
\text { Stephen J. Scotti, Carl J. Martin, Stephen H. Lucas }\end{array}$} & 8. Performing Organization Report No. \\
\hline \multicolumn{2}{|c|}{ 9. Performing Organization Name and Address } & $\begin{array}{l}\text { 10. Work Unit No. } \\
505-43-81-01\end{array}$ \\
\hline \multicolumn{2}{|c|}{$\begin{array}{l}\text { NASA Langley Research Center } \\
\text { Hampton, VA } 23665\end{array}$} & 11. Contract or Grant No. \\
\hline \multirow{2}{*}{\multicolumn{2}{|c|}{$\begin{array}{l}\text { 12. Sponsoring Agency Name and Address } \\
\text { National Aeronautics and Space Administration } \\
\text { Washington, DC } 20546\end{array}$}} & $\begin{array}{l}\text { 13. Type of Report and Period Covered } \\
\text { Technical Memorandum }\end{array}$ \\
\hline & & 14. Sponsoring Agency Code \\
\hline \multicolumn{3}{|c|}{$\begin{array}{l}\text { 15. Supplementary Notes Stephen J. Scotti, Langley Research Center, Hampton, VA, } \\
\text { Carl J. Martin, PRC Kentron Inc., Hampton, VA and Stephen H. Lucas, VIRA, Inc. } \\
\text { Hampton, VA. } \\
\text { Presented at the AIAA/ASME, et al., 29th Structures, Structural Dynamics and } \\
\text { Materials Conference, April 18-20, 1988, Williamsburg, Virginia. }\end{array}$} \\
\hline \multicolumn{3}{|c|}{$\begin{array}{l}\text { 16. Abstract } \\
\text { A methodology for using optimization in designing metallic cooling jackets for } \\
\text { scramjet engines is presented. The optimal design minimizes the required } \\
\text { coolant flow rate subject to temperature, mechanical-stress, and } \\
\text { thermal-fatigue-life constraints on the cooling-jacket panels, and Mach-number } \\
\text { and pressure constraints on the coolant exiting the panel. The analytical } \\
\text { basis for the methodology is presented, and results for the optimal design of } \\
\text { panels are shown to demonstrate its utility. }\end{array}$} \\
\hline $\begin{array}{l}\text { 17. Key Words (Suggested by Authors(s)) } \\
\text { metallic cooling jackets } \\
\text { scramjet engines }\end{array}$ & $\begin{array}{r}\text { 18. Distribution S } \\
\text { Ur } \\
\text { SL }\end{array}$ & $\begin{array}{l}\text { nent } \\
\text { assified - Unlimited } \\
\text { category - } 39\end{array}$ \\
\hline $\begin{array}{l}\text { 19. Security Classif.(of this report) } \\
\text { Unclassified }\end{array}$ & $\begin{array}{l}\text { 20. Security Classif. (of this pas } \\
\text { Unclass if ied }\end{array}$ & \begin{tabular}{|l|l|} 
21. No. of Pages & 22. Price \\
12 & $\mathrm{AO2}$ \\
\end{tabular} \\
\hline
\end{tabular}

